\title{
Relationship of Airborne Botrytis cinerea Conidium Concentration to Tomato Flower and Stem Infections: A Threshold for De-leafing Operations
}

\author{
O. Carisse, Agriculture and Agri-Food Canada, 430 Gouin Boulevard, St-Jean-sur-Richelieu, Quebec, Canada J3B 3E6; and H. Van
} der Heyden, Compagnie de recherche Phytodata Inc., 291 Rue de la coopérative, Sherrington, Québec, Canada, J01 2N0

\begin{abstract}
Carisse, O., and Van der Heyden, H. 2015. Relationship of airborne Botrytis cinerea conidium concentration to tomato flower and stem infections: A threshold for de-leafing operations. Plant Dis. 99:137-142.

Gray mold, caused by Botrytis cinerea, is an important threat for tomato greenhouse producers. The influence of airborne conidia concentration (ACC) on both flower and stem-wound infections was studied in a greenhouse maintained at a temperature of 15,20 , or $25^{\circ} \mathrm{C}$ using diseased tomato leaves as the unique source of dry inoculum. Spore samplers were used to monitor ACC, and a previously developed real-time qPCR assay was used to quantify airborne $B$. cinerea conidia. The proportion of infected flowers remained low at $\mathrm{ACC}<10 \mathrm{conidia} / \mathrm{m}^{3}$; above this concentration, flower infection increased with increasing ACC. The influence of ACC on proportion of infected flowers was well

described by a sigmoid model $\left(R^{2}=0.90\right.$ to 0.92$)$. The mean proportion of infected stem wounds over the three trials was 0.021 ; no infected wounds were observed at ACC $<100$ conidia $/ \mathrm{m}^{3}$. Based on logistic regression, the probability that a stem becomes infected increased rapidly with mean probabilities of 0.24 and 0.87 at ACCs of 315 and 3,161 conidia $/ \mathrm{m}^{3}$, respectively. The results suggest that the amount of airborne $B$. cinerea inoculum in the greenhouse is often above the action threshold for flower infection and that monitoring airborne $B$. cinerea inoculum could help in timing de-leafing operations.
\end{abstract}

Botrytis cinerea is a pathogenic and necrotrophic fungus of several fruit and vegetable crops that causes pre- and postharvest rot. Gray mold, caused by $B$. cinerea, is one of the most commonly occurring diseases in greenhouse vegetable crops in Canada (1), which are among the country's highest-value horticultural commodities. Total yield losses attributed to gray mold are significant and average 10 to $20 \%$ (1). However, when conditions are favorable for disease development, crop losses can reach up to $40 \%$ at the end of a cropping period (1). On tomato (Lycopersicon esculentum Mill.), B. cinerea can infect all aerial plant parts, although most crop losses are due to flower infections, which result in direct losses of fruit, and to stem-wound infections, which may induce the death of an entire plant, causing losses of fruit production over several months $(14,21,27)$.

Tomato plants are susceptible to $B$. cinerea infection at any growth stage, but tender, recently injured, and senescing or dead tissues are most susceptible. Under favorable conditions, large numbers of conidia are produced on lesions, blighted tissues, and plant debris. These conidia are disseminated by air currents and, to a lesser extent, by splashing water, and are responsible for initiating new disease cycles. In addition to the amount of conidia, disease progress is influenced by temperature and relative humidity. Briefly, optimal conditions for infection are tissue wetness or high relative humidity ( $>90 \%$ ) for at least $8 \mathrm{~h}$ at a temperature of 15 to $20^{\circ} \mathrm{C}$. B. cinerea colonizes infected plant tissues at temperatures up to $24^{\circ} \mathrm{C}$. Consequently, the regulation of temperature and humidity conditions in the greenhouse plays a key role in gray mold management $(6,12,13,18,19,22)$. However, research on the influence of relative humidity on flower infection showed that maintaining low relative humidity in a greenhouse helped reduce flower infection but not stem infection (7).

Corresponding author: Odile Carisse, E-mail: odile.carisse@agr.gc.ca

Accepted for publication 18 July 2014.

http://dx.doi.org/10.1094/PDIS-05-14-0490-RE

This article is in the public domain and not copyrightable. It may be freely reprinted with customary crediting of the source. The American Phytopathological Society, 2015.
De-leafing is necessary to maintain high fruit quality and quantity. However, when a tomato plant is de-leafed, spores are shaken from the lesions and become airborne; the spores are then transported by air currents in the greenhouse and settle onto the fresh stem wounds made by de-leafing $(5,24,25)$. Within a week, there can be new lesions in some of the stem wounds. Consequently, it is difficult to bring $B$. cinerea under control once it has become established in a greenhouse. Despite the importance of managing greenhouse conditions, this approach by itself is not sufficient to control gray mold. Fungicides have been registered for gray mold management, but it is difficult to achieve good coverage and reach all infection sites. In addition, $B$. cinerea has developed resistance to several fungicides, including synthetic and biological ones $(15,17)$. Reliance on fungicides should thus be reduced as much as possible. One way to achieve this reduction is to apply fungicides based on risk and thus avoid needless fungicide sprays.

To implement integrated gray mold management, it is essential to acquire knowledge on inoculum (sources, amount, and dynamics). The relationship between inoculum concentration and disease development has been studied using aqueous spore solutions (7). However, under commercial conditions, aqueous inoculum may not reflect the real situation. Monitoring airborne inoculum using spore samplers and DNA-based assays for quantification has proven to be a good tool for estimating disease risk when making management decisions for several aerially dispersed diseases, including Botrytis leaf blight of onion (Botrytis squamosa), grape powdery mildew (Erysiphe necator), and Sclerotinia sclerotiorum infection $(2,4,20,26)$. Hence, the specific objective of this study was to establish the relationship between airborne inoculum concentration and flower and stem-wound infections and to establish a potential action threshold for de-leafing operations.

\section{Materials and Methods}

Inoculum and plant production. $B$. cinerea was isolated from diseased tomato leaves and fruits collected in experimental and commercial greenhouses. The $B$. cinerea isolates were stored at $2{ }^{\circ} \mathrm{C}$ in sterilized soil, and a total of five isolates were used for inoculation. Prior to inoculation, the isolates were grown on V8 agar (9-cm petri dishes) incubated for 10 to 14 days at room temperature (approximately $20^{\circ} \mathrm{C}$ with a 12 -h photoperiod). Spores of $B$. cinerea were collected by flooding the cultures with sterile water 
and gently dislodging the spores with a glass rod. The resulting spore suspension, adjusted to $10^{4}$ spores $/ \mathrm{ml}$, was used to inoculate detached tomato leaves, which were kept on wet paper in plastic trays at room temperature. To maintain high humidity, a plastic lid was placed on top of each tray.

All trials were conducted at the Agriculture and Agri-Food Canada Horticulture Research and Development Centre, located in StJean-sur-Richelieu, Quebec. Seeds of the tomato cultivar 'Mariachi' were germinated in a commercial potting mix in 72-cell pack trays cut in 4 pieces of 18 cells and placed on a bench in a propagation house. The seedlings were transplanted at the cotyledon stage into $20-\mathrm{cm}$-diameter pots filled with potting mix. The plants were liquid-fed with $225 \mathrm{ppm}$ of 15-15-30 (15\% N:15\% $\mathrm{P}_{2} \mathrm{O}_{5}: 30 \%$ $\left.\mathrm{K}_{2} \mathrm{O}\right)$ fertilizer for the first 5 weeks and then with 6-11-31 (6\% $\mathrm{N}: 11 \% \mathrm{P}_{2} \mathrm{O}_{5}: 31 \% \mathrm{~K}_{2} \mathrm{O}$ ) fertilizer at a rate of $1.5 \mathrm{~g} /$ liter with calcium nitrate at a rate of $0.85 \mathrm{~g} /$ liter. The temperature in the greenhouse was maintained at $22 \pm 2^{\circ} \mathrm{C}$ during the day and at $15 \pm 2{ }^{\circ} \mathrm{C}$ during the night until inoculation.

Inoculation procedure. When tomato plants reached the stage of four or five flower trusses per plant, which happened approximately 6 weeks after transplanting, 18 plants were moved to a greenhouse chamber. Ten randomly selected plants were tagged, and four leaves at the bottom of each tagged plant were pruned. All tomato plants (tagged and untagged plants) were moved to another greenhouse chamber. Prior to introducing inoculum into the greenhouse chamber, for each of the tagged plants, the number of flowers per flower truss was counted on the four youngest trusses, and the other trusses were removed. New flower trusses were removed as they appeared. The plants were inoculated by placing the previously infected detached tomato leaves on the greenhouse floor. The infected leaves were evenly distributed on the greenhouse floor, and different densities of leaves and of leaf area sporulating were used to create various airborne conidia concentrations (ACCs). Trials with no previously infected tomato leaves served as control. The relative humidity in the greenhouse chamber was maintained at $95 \pm 5 \%$.

Rotating-arm spore samplers with retracting-type sampling heads (Compagnie de recherche Phytodata Inc., Sherrington, Quebec, Canada) were installed in the greenhouse (four samplers per greenhouse chamber). Daily aerial concentration of $B$. cinerea conidia was monitored from 8 A.M. to 4 P.M. ( $50 \%$ of the time) for a total of $4 \mathrm{~h}$ of sampling. $B$. cinerea spores present on the sampling surfaces $\left(40 \mathrm{~mm}^{2}\right)$ were estimated using a TaqMan real-time PCR assay (3). Conidia counts were converted to spore concentrations (conidia $/ \mathrm{m}^{3}$ of air) by accounting for the sampling rate $(20.65 \mathrm{li}-$ ters/min) and the duration of the sampling period (4 h). After an 8$\mathrm{h}$ period of exposure to $B$. cinerea airborne inoculum (from 8 A.M. to 4 P.M.), the tomato plants were moved to another greenhouse chamber, which was maintained at a relative humidity of $96 \pm 2 \%$ and a temperature of $20 \pm 2{ }^{\circ} \mathrm{C}$. The whole procedure was repeated 30 times at each of the selected temperatures $\left(15,20\right.$, and $\left.25^{\circ} \mathrm{C}\right)(5$ and 25 times without and with introduced inoculum, respectively).

Disease assessment and statistical analysis. Flower and stemwound infections were assessed daily by looking at all flowers and all stem wounds 7 and 14 days after introduction in the greenhouse (exposure to inoculum). A flower was considered to be infected if brown lesions extended to the pedicel or if $B$. cinerea spores were present. A previously described TaqMan real-time PCR assay was used to determine that these spores belonged to B. cinerea (3). A stem wound was considered to be infected if brown lesions extended at least $5 \mathrm{~mm}$ out from the leaf removal scar (7). The proportion of infected flowers was calculated as $P_{f}=x_{f} f(n \times N)$, where $x_{f}$ is the total number of infected flowers, $n$ is the number of flowers per plant, and $N$ is the number of tomato plants sampled $(N=10)$. Similarly, the proportion of infected stem wounds was calculated as $P_{a}=x_{s} /(n \times N)$, where $x_{s}$ is the total number of infected stem wounds, $n$ is the number of stem wounds $(n=4)$ per plant, and $N$ is the number of tomato plants sampled $(N=10)$. In addition, because of the low incidence of stem-wound infection, the incidence of infected tomato stems (plants) was calculated as binary data with a notation of 1 and 0 for stems with at least one stem wound infected and absence of infection, respectively. To stabilize variances, $B$. cinerea ACC was $\log$-transformed as $x=\log \left(\right.$ conidia $/ \mathrm{m}^{3}$ $+1)$. To describe the pattern of proportion of infected flowers as a function of ACC, a sigmoid model (equation 1) was fitted to the data as follows:

$$
P_{f}=\frac{a}{1+e^{\frac{x-x_{0}}{b}}}
$$

where $P_{f}$ is the proportion of infected flowers, $a$ is the asymptote, $b$ is the rate of increase in proportion of infected flowers and is equal to the slope of the linear portion of the sigmoid curve, $x$ is the logtransformed ACC, and $x_{0}$ represents the log-transformed ACC at which $P_{f}$ is one-half of the maximum. For the purpose of measuring the accuracy of model fit, the concordance correlation coefficient (CCC) was used as a measure of accuracy (16). The CCC was calculated as $r \times \mathrm{C}_{b}$, where $r$ is the Pearson product-moment correlation between observed and predicted proportion of diseased flowers and $C_{b}$ is a bias coefficient. The bias coefficient is the deviation of the best-fitting line from the concordance line (perfect agreement between observed and predicted values), which is a straight line with an intercept of 0 and a slope of 1 (16).

The relationship between incidence of diseased stems and ACC was modeled with logistic regression because of the dichotomous nature of diseased stems, low observed incidence of infected stem wounds, and assumed binomial distribution of errors. Simple logistic regression was used to estimate the probability of stem infection as a function of ACC. The simple logistic model is based on a linear relationship between the natural logarithm $(\mathrm{ln})$ of the odds of a stem being infected and airborne conidia concentration in the greenhouse (ACC) expressed as:

$$
\ln (O)=\ln \left(\frac{p}{1-p}\right)=\beta_{0}+\beta_{1} A C C+\varepsilon
$$

where $O$ is the odds of the event (here a stem being infected by $B$. cinerea $), p$ is the probability that a stem is infected, $p /(1-p)$ is the odds ratio, $\beta_{0}, \beta_{1}$, and $\varepsilon$ are the intercept, the slope, and the random error, respectively. The estimated probability of stem infection was calculated as:

$$
\hat{p}=\frac{e^{\hat{\beta}_{0}+\hat{\beta}_{1} A C C}}{1+e^{\hat{\beta}_{0}+\hat{\beta}_{1} A C C}}
$$

Statistical analyses were conducted using the SAS software program (version 9.3; SAS Institute Inc., Cary, NC).

\section{Results}

When inoculum was introduced in the greenhouse chamber, the mean and maximum airborne inoculum concentrations were 182.9 and 2,134.9 conidia $/ \mathrm{m}^{3}, 230.9$ and $2,635.7$ conidia $/ \mathrm{m}^{3}$, and 277.3 and $3,189.2$ conidia $/ \mathrm{m}^{3}$ for the trials conducted at 15,20 , and $25^{\circ} \mathrm{C}$, respectively. In absence of introduced inoculum, airborne conidia concentration was below 0.5 conidia $/ \mathrm{m}^{3}$. The mean proportion of infected flowers over the three trials was 0.16 , with means of $0.14,0.16$, and 0.16 for the trials conducted at 15,20 , and $25^{\circ} \mathrm{C}$, respectively. Regardless of the temperature in the greenhouse, the proportion of infected flowers remained low when the $B$. cinerea ACC in the greenhouse was below 10 conidia $/ \mathrm{m}^{3}$. Above this concentration, flower infections increased with increasing $B$. cinerea conidium concentrations (Fig. 1). The relationship between the proportion of infected flowers and the log-transformed ACC was not linear and was best described by a sigmoid model $\left(R^{2}=0.90\right.$ to 0.92 ) (Table 1$)$. The estimated asymptotes $(a)$ were $0.88,1.03$, and 0.98 , the estimated rates of disease progress were $0.44,0.51$, and 0.44 , and the log-transformed ACC +1 values at which the proportion of infected flowers was equal to 0.5 were estimated at 2.23 , 2.47 , and 2.25 , for the trials conducted at 15,20 , and $25^{\circ} \mathrm{C}$, respectively (Table 1). When the data from the trials conducted at different temperatures were pooled, the proportion of infected flowers as 
a function of log-transformed ACC was described by the following model (Fig. 1, Table 1):

$$
P_{f}=\frac{0.9586}{1+e^{\frac{x-2.3086}{0.4665}}}
$$

where $P_{f}$ is the proportion of infected flowers and $x$ is the logtransformed conidia $/ \mathrm{m}^{3}$. When the observed proportions of infected flowers were regressed against the predicted proportions using estimates provided in Table 1, the correlation coefficients varied from 0.95 to 0.96 , with coefficients of bias varying from 0.90 to 0.92 for CCC varying from 0.85 to 0.87 (Fig. 2).

The mean proportion of infected stem-wounds over the three trials was 0.021 , with means of $0.016,0.020$, and 0.029 for the trials conducted at 15,20 , and $25^{\circ} \mathrm{C}$, respectively. No infected wounds were observed when the $B$. cinerea ACC in the greenhouse was below 100 conidia $/ \mathrm{m}^{3}$ (Fig. 3). The overall incidence of diseased stems was $8.1 \%(5.7,8.0$, and $10.7 \%$, for temperature in the greenhouse of 15,20 , and $25^{\circ} \mathrm{C}$, respectively). Based on the logistic regression, regardless of the temperature in the greenhouse, there was a significant effect of log-transformed $\mathrm{ACC}+1$ on the incidence of infected stem as illustrated by the estimated positive values of the $\beta_{1}$ parameters of $2.723,2.598$, and 5.426 , for temperatures of 15,20 , and $25^{\circ} \mathrm{C}$, respectively (Fig. 4, Table 2). The probability that a stem becomes infected as a function of logtransformed $\mathrm{ACC}+1$ was calculated using equation 3 with the estimated values of the intercept and slope (Fig. 4, Table 2). Regardless of the temperature, at airborne conidia concentrations below 100 conidia $/ \mathrm{m}^{3}(\log$ ACC $+1=2)$, the probability that a tomato stem becomes infected was low with probabilities of less than $0.05,0.08,0.03$, and 0.06 for temperatures of $15,20,25^{\circ} \mathrm{C}$, and pooled temperatures, respectively. This probability increased rapidly with increasing airborne conidia concentrations (Fig. 5). For example, at an airborne conidia concentration of 315 conid$\mathrm{ia} / \mathrm{m}^{3}\left(\log\right.$ conidia $\left./ \mathrm{m}^{3}+1=2.5\right)$, this probability was $0.18,0.24$, 0.30 , and 0.24 for temperatures of $15,20,25^{\circ} \mathrm{C}$, and pooled temperatures, respectively. The probability was highest at the airborne conidia concentration of 3,161 conidia $/ \mathrm{m}^{3}\left(\log\right.$ conidia $/ \mathrm{m}^{3}+1=$ 3.5 ) with values of $0.78,0.81,0.99$, and 0.87 for temperature of 15 , $20,25^{\circ} \mathrm{C}$, and pooled temperatures, respectively (Fig. 5).

\section{Discussion}

Managing gray mold in greenhouse-grown tomatoes is difficult owing to the combined influence of the absence of resistant tomato cultivars (23), the reduced efficacy of fungicides caused by an

Table 1. Estimated parameters of the sigmoid model (equation 1) for the progress of flower infections caused by Botrytis cinerea as a function of $\log$-transformed airborne conidia concentration $\left(\log \left(\right.\right.$ conidia $\left.\left./ \mathrm{m}^{3}+1\right)\right)$ in greenhouse chamber maintained at 15,20 , and $25^{\circ} \mathrm{C}$

\begin{tabular}{lcccc}
\hline Temperature & $\boldsymbol{R}^{\mathbf{2}}{ }_{\text {adj }}$ & $\mathbf{a}(\mathbf{S E})^{\mathbf{z}}$ & $\mathbf{b}(\mathbf{S E})^{\mathbf{z}}$ & $\boldsymbol{x}_{\mathbf{0}}(\mathbf{S E})^{\mathbf{z}}$ \\
\hline $15^{\circ} \mathrm{C}$ & 0.91 & 0.8789 & 0.4387 & 2.2173 \\
& & $(0.0288)$ & $(0.0233)$ & $(0.0442)$ \\
$20^{\circ} \mathrm{C}$ & 0.90 & 1.0284 & 0.5132 & 2.4708 \\
& & $(0.0482)$ & $(0.0293)$ & $(0.0662)$ \\
$25^{\circ} \mathrm{C}$ & 0.92 & 0.9757 & 0.4440 & 2.2472 \\
& & $(0.0295)$ & $(0.0213)$ & $(0.0421)$ \\
Pooled & 0.91 & 0.9586 & 0.4665 & 2.3086 \\
& & $(0.0201)$ & $(0.0144)$ & $(0.0292)$ \\
\hline
\end{tabular}

${ }^{z}$ Value of the estimate followed by the value of its standard error (SE) in parentheses.
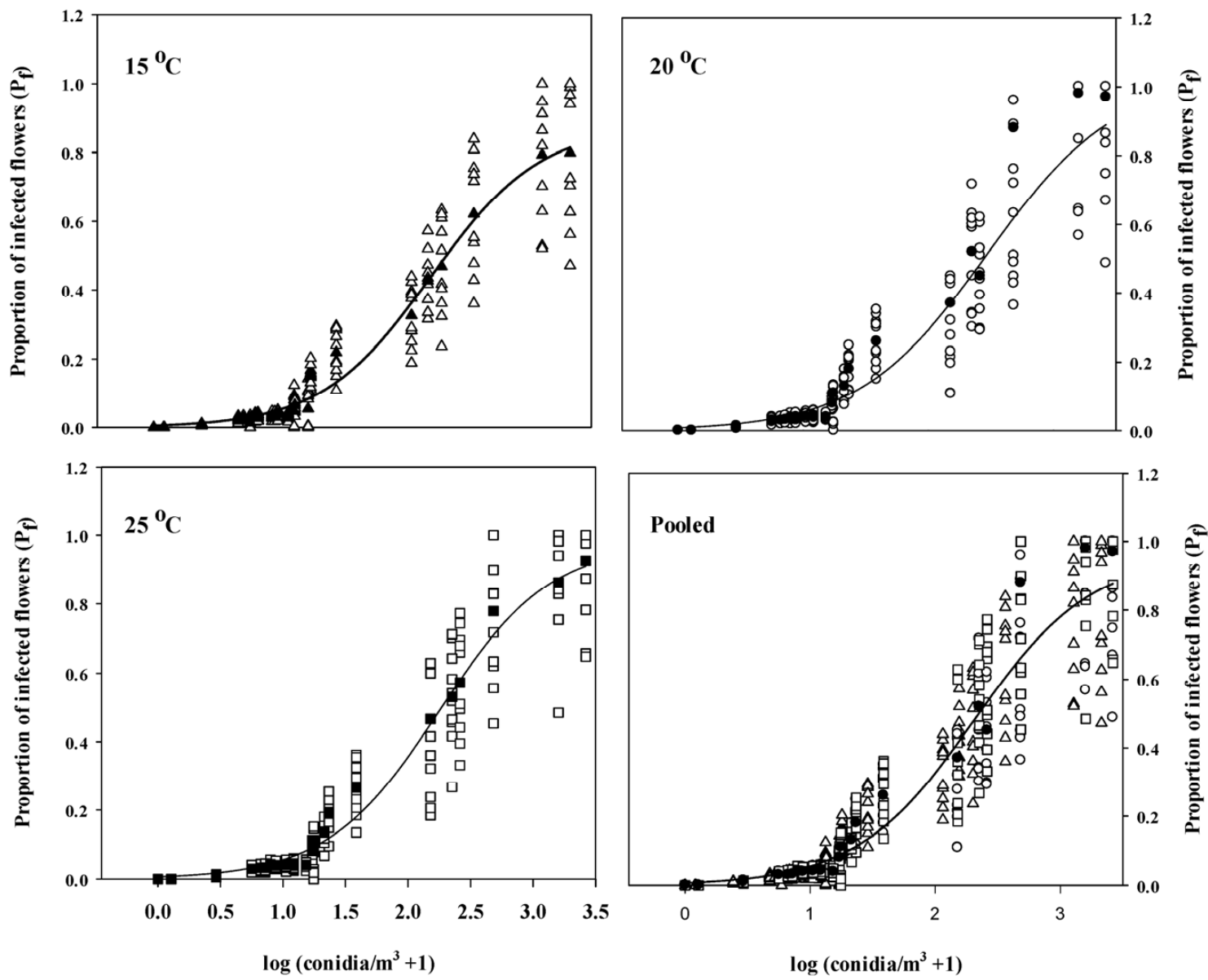

Fig. 1. Progress of proportion of flowers infected by airborne conidia of Botrytis cinerea as a function of log-transformed airborne conidia concentration in greenhouse chambers adjusted to $15,20,25^{\circ} \mathrm{C}$, and pooled data. Empty triangles, circles, and squares represent the observations made at the greenhouse temperatures of 15,20 , and $25^{\circ} \mathrm{C}$, respectively, while the same filled symbols represent the means over the 10 plants. Lines represent the predicted values calculated with equation 1 and estimates presented in Table 1. 
increased proportion of resistant isolates (28), de-leafing, and the plants' requirement for relative humidity and temperature that also favors disease development $(5,7)$. Understanding the factors that trigger the development of gray mold epidemics is essential for designing and implementing effective management strategies. This need has prompted research addressing the effects of greenhouse conditions on gray mold development in several countries where the disease is prevalent $(5,7,11,21)$.

Previous studies on the influence of greenhouse conditions, mostly relative humidity, dew duration, and temperature, on infection of tomato plants by $B$. cinerea were conducted using aqueous conidial suspensions as inoculum (7). In greenhouses, however, $B$. cinerea conidia are disseminated mostly by air currents and are deposited on tissue surfaces as dry conidia. Inoculation with dry conidia poses technical problems: for instance, it is difficult to control the amount of airborne inoculum to which the plants are exposed. In addition, with dry inoculum it is almost impossible to create replicates (repeated inoculation with exactly the same amount of inoculum). In the present study, these limitations were circumvented by repeating the experiment several times with different densities of infected tomato leaves on the greenhouse floor and by measuring airborne inoculum. Nevertheless, for flower infection, the results of this study support previous reports suggesting that flower infection by $B$. cinerea increases with increasing temperature in the greenhouse (7). Under optimal relative humidity conditions, maximum proportions of infected flowers were 0.81 , 0.98 , and 0.99 infected flowers for temperatures in the greenhouse of 15,20 , and $25^{\circ} \mathrm{C}$, respectively. The influence of airborne conidia concentration was similar for the three temperatures and was well explained by a sigmoid model. The sigmoid rates of increase in the proportion of infected flowers were $0.43,0.51$, and 0.44 for green- house temperatures of 15,20 , and $25^{\circ} \mathrm{C}$, respectively. These results suggest that $B$. cinerea airborne inoculum could be a good risk indicator for gray mold. It is worth noting that the airborne inoculum at which the proportion of infected flowers reached $50 \%$ were similar for the three temperatures in the greenhouse, with values of 2.23, 2.47, and 2.25 log-transformed ACC +1 , which correspond

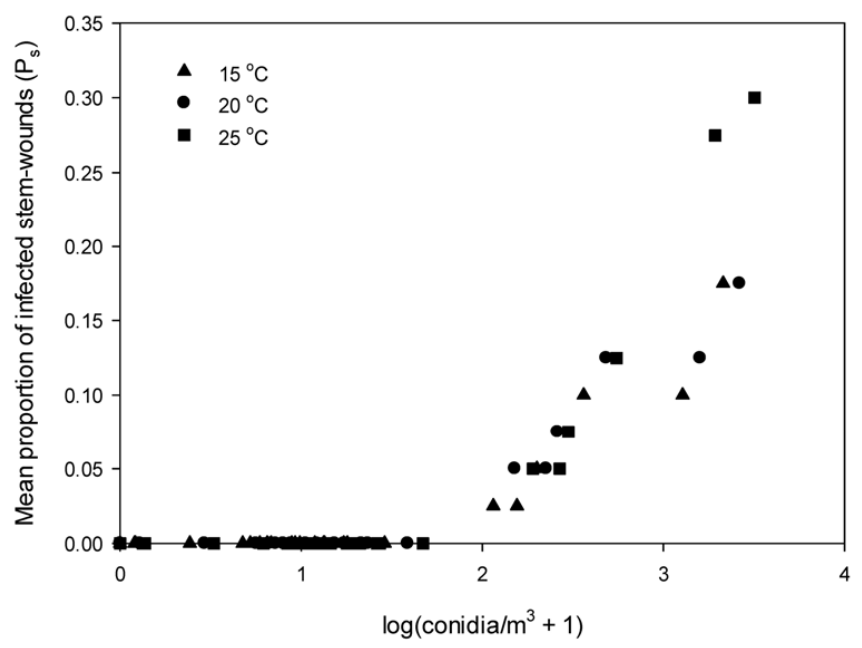

Fig. 3. Progress of proportion of stem-wounds infected by airborne conidia of Botrytis cinerea as a function of log-transformed airborne conidia concentration in greenhouse chambers adjusted to 15,20 , and $25^{\circ} \mathrm{C}$. Triangles, circles, and squares represent the observations made at greenhouse temperatures of 15,20 , and $25^{\circ} \mathrm{C}$, respectively.
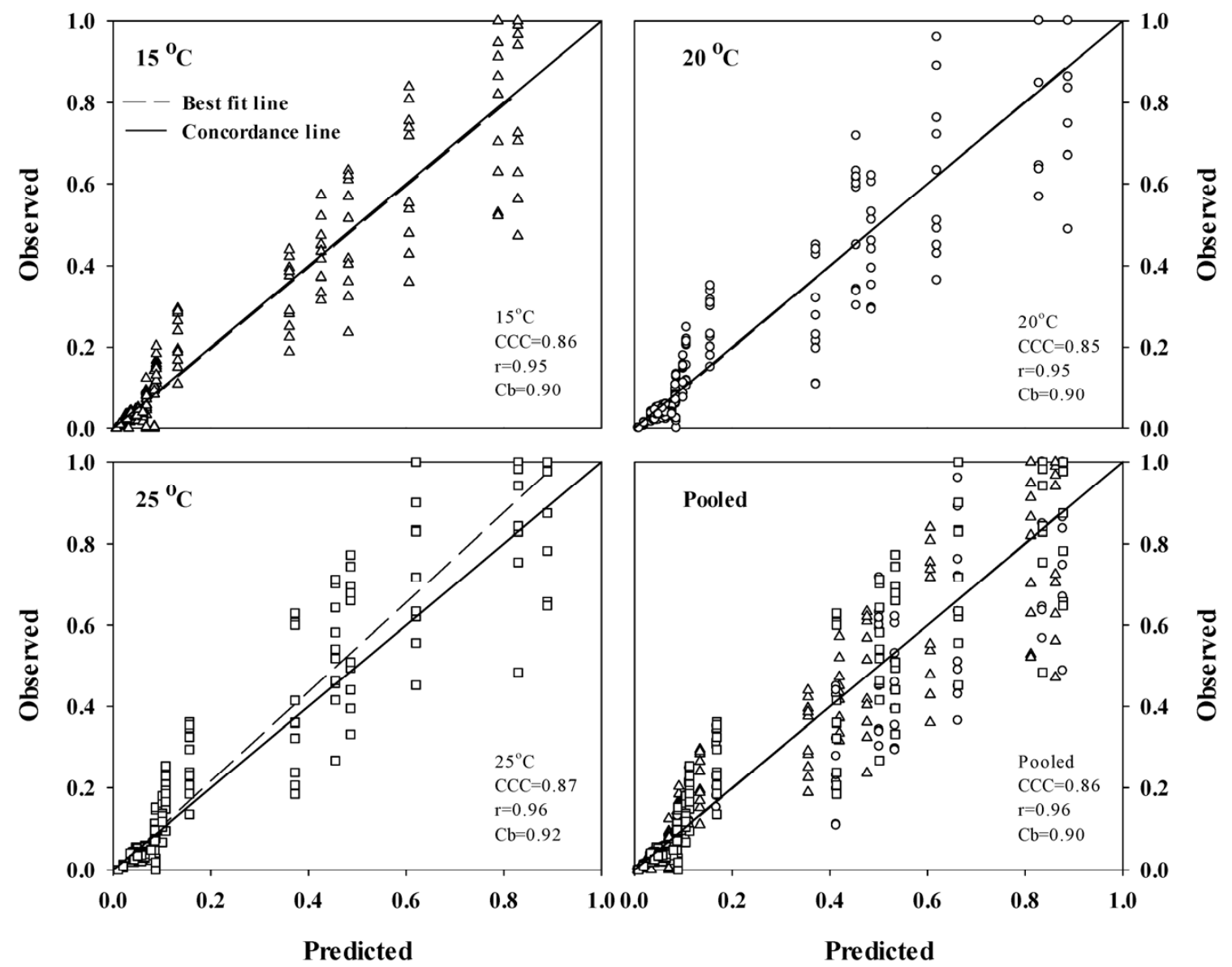

Fig. 2. Relationship between observed and predicted proportions of flowers infected by airborne conidia of Botrytis cinerea at greenhouse temperatures of $15,20,25^{\circ} \mathrm{C}$, and pooled data. Empty triangles, circles, and squares represent the values obtained for temperatures in the greenhouse of 15,20 , and $25^{\circ} \mathrm{C}$, solid and broken lines represent the concordance and best fit lines, respectively. 
to 170,295 , and 178 conidia $/ \mathrm{m}^{3}$ at temperatures of 15,20 , and $25^{\circ} \mathrm{C}$, respectively. In this study, no flower infections were observed when $B$. cinerea airborne inoculum was below 10 conid$\mathrm{ia} / \mathrm{m}^{3}$.

For the stem-wound infection, regardless of the temperature in the greenhouse, the proportion of stem-wounds infected by $\mathrm{B}$. $\mathrm{Ci}$ nerea was low with an overall mean of 0.02 . However, the proportion reached $0.16,0.18$, and 0.28 at temperatures in the greenhouse of 15,20 , and $25^{\circ} \mathrm{C}$, respectively. These results are different than those reported by Eden et al. (7) who reported that tomato stemwounds decrease as the temperature in the greenhouse increases. Considering that the economic threshold for stem-wound infections is considered to be near zero, given that only one infected wound may cause the death of the plant, analysis was conducted with incidence of infected stems. Based on the logistic regression, for all temperatures in the greenhouse, there was a significant effect of log-transformed ACC +1 on the incidence of infected stem. Regardless of the temperature, at airborne conidia concentration below 100 conidia $/ \mathrm{m}^{3}$, the probability that a tomato stem becomes infected was low, with probabilities of less than $0.05,0.08,0.03$, and 0.06 for temperatures of $15,20,25^{\circ} \mathrm{C}$, and pooled temperatures, respectively. The probability that a tomato stem becomes infected increased rapidly with increasing airborne conidia concentration. At airborne inoculum of 315 conidia $/ \mathrm{m}^{3}$ this probability was $0.18,0.24,0.30$, and 0.24 for temperatures of $15,20,25^{\circ} \mathrm{C}$, and pooled temperatures, respectively, while at $3,161 \mathrm{conidia} / \mathrm{m}^{3}$, the probability increased to $0.78,0.81,0.99$, and 0.87 for temperatures of $15,20,25^{\circ} \mathrm{C}$, and pooled temperatures, respectively.

Greenhouse tomato plants are grown as single or double stems. To increase light exposure, accelerate the ripening of fruit, and facilitate plant training, tomato leaves are removed from the bottom to the top starting at the time of ripening of the first fruit cluster until the end of the season (12). Removing lower tomato leaves increases air circulation and hence reduces the risk of $B$. cinerea infection $(8,19)$. However, this advantage is counterbalanced by the infection of the tomato stem wound that de-leafing creates for $B$.
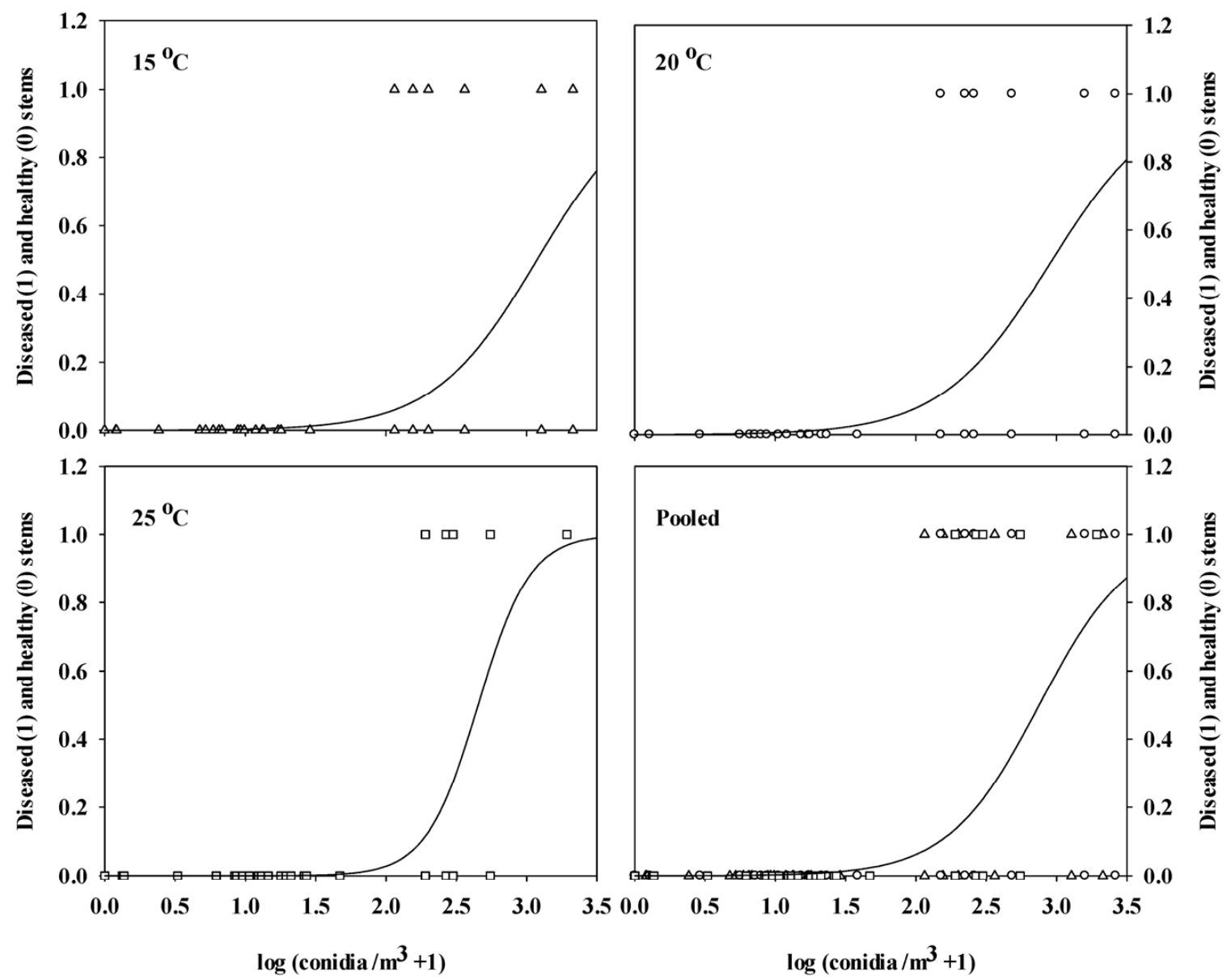

Fig. 4. Incidence of tomato stems infected by airborne conidia of Botrytis cinerea as a function of log-transformed airborne conidia concentration in greenhouse chambers adjusted to $15,20,25^{\circ} \mathrm{C}$, and pooled data. Empty triangles, circles, and squares represent the observations made at temperatures in the greenhouse of 15,20 , and $25^{\circ} \mathrm{C}$, respectively. Lines represent the predicted values calculated with equation 2 and estimates presented in Table 2.

Table 2. Statistic associated with the logistic regression of incidence of infected stem as a function of log-transformed airborne conidia concentration (log $\left(\right.$ conidia $\left./ \mathrm{m}^{3}+1\right)$ ) in greenhouse chamber maintained at 15,20 , and $25^{\circ} \mathrm{C}$

\begin{tabular}{|c|c|c|c|c|c|}
\hline Temperature & Source & Estimate (SE) & Wald Chi-square & $P>\mathrm{Chi}^{2}$ & Odds ratio $^{z}$ \\
\hline \multirow[t]{2}{*}{$15^{\circ} \mathrm{C}$} & Intercept & $-8.371(1.472)$ & 32.343 & $<0.0001$ & \\
\hline & $\log (\mathrm{ACC}+1)$ & $2.723(0.530)$ & 26.404 & $<0.0001$ & 15.225 \\
\hline \multirow[t]{2}{*}{$20^{\circ} \mathrm{C}$} & Intercept & $-7.665(1.166)$ & 43.206 & $<0.0001$ & \\
\hline & $\log (\mathrm{ACC}+1)$ & $2.598(0.435)$ & 35.605 & $<0.0001$ & 13.437 \\
\hline \multirow[t]{2}{*}{$25^{\circ} \mathrm{C}$} & Intercept & $-14.405(3.374)$ & 18.223 & $<0.0001$ & \\
\hline & $\log (\mathrm{ACC}+1)$ & $5.426(1.314)$ & 17.046 & $<0.0001$ & 227.282 \\
\hline \multirow[t]{2}{*}{ Pooled } & Intercept & $-8.914(0.854)$ & 108.875 & $<0.0001$ & \\
\hline & $\log (\mathrm{ACC}+1)$ & $3.099(0.316)$ & 95.895 & $<0.0001$ & 22.165 \\
\hline
\end{tabular}

${ }^{\mathrm{z}}$ The odds ratio is calculated as $p /(1-p)$, where $p$ is the probability that a stem is infected. 


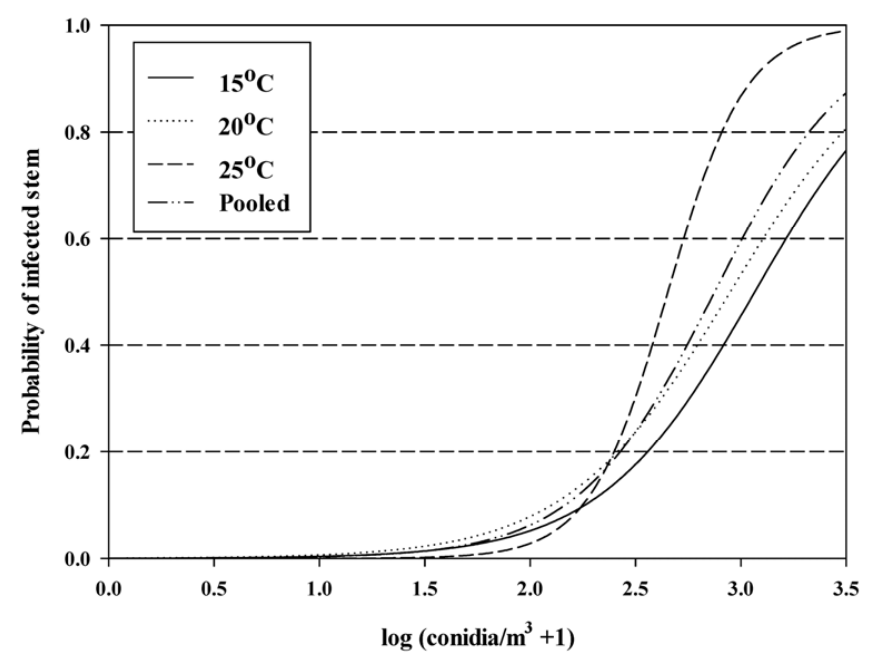

Fig. 5. Probability of stem infection as a function of log-transformed airborne conidia concentration in greenhouse chambers adjusted to $15,20,25^{\circ} \mathrm{C}$, and pooled data. Lines represent the values calculated with equation 3 and estimates presented in Table 2.

cinerea, especially as de-leafing and other grower activities may cause increases in airborne concentration of $B$. cinerea spores in the greenhouse $(9,10)$.

Preventing wound infection with conventional or biological fungicide sprays is difficult, mostly because of the difficulty of reaching and sufficiently covering all the pruning wounds present in a greenhouse. Wound infection could, however, be managed by adopting certain cultural practices, such as irrigating early in the morning to favor rapid drying of the scars $(6,12)$, using optimal deleafing techniques (5), and de-leafing on dry days and when inoculum in the greenhouse is low. The results of the present study suggest that one of the most critical factors affecting stem-wound infection by $B$. cinerea is the concentration of conidia in the greenhouse. Given that efficient, low-cost techniques are now available to sample air and quantify airborne $B$. cinerea conidium concentration (3), growers should be more interested in adopting them.

\section{Acknowledgments}

This work was financially supported by Agriculture and Agri-Food Canada and Phytodata Inc. The authors thank Pierre-Yves Verroneau for providing technical assistance and Luc Brodeur for fruitful discussions and guidance for conducting the experiments.

\section{Literature Cited}

1. Anonymous, 2011. Crop Profile for Greenhouse Tomato in Canada. Retrieved from http://publications.gc.ca/collections/collection_2009/agr/A11810-24-2006E.pdf

2. Carisse, O., Bacon, R., and Lefebvre, A. 2009. Grape powdery mildew (Erysiphe necator) risk assessment based on airborne conidium concentration. Crop Prot. 28:1036-1044.

3. Carisse, O., Tremblay, D. M., and Lefebvre, A. 2014. Aerobiology of Botrytis cinerea in raspberry, strawberry, and grape: Analysis of airborne inoculum progress curves. Plant Pathol. (In press.)

4. Carisse, O., Tremblay, D. M., Lévesque, C. A., Gindro, K., Ward, P., and Houde, A. 2009. Development of a TaqMan real-time PCR assay for quantification of airborne conidia of Botrytis squamosa and management of Botrytis leaf blight of onion. Phytopathology 99:1273-1280.
5. Decognet, V., Ravetti, F., Martin, C., and Nicot, P. C. 2010. Improved leaf pruning reduces development of stem cankers caused by grey mould in greenhouse tomatoes. Agron. Sustainable Devel. 30:465-472.

6. Dik, A. J., and Wubben, J. P. 2004. Epidemiology of Botrytis cinerea diseases in greenhouses. Pages 319-333 in: Botrytis: Biology, Pathology and Control. Y. Elad, B. Williamson, P. Tudzynski, and N. Delen, eds. Kluwer Academic Publishers, Dordrecht, The Netherlands.

7. Eden, M. A., Hill, R. A., Beresford, R., and Stewart, A. 1996. The influence of inoculum concentration, relative humidity, and temperature on infection of greenhouse tomatoes by Botrytis cinerea. Plant Pathol. 45:795-806.

8. Elad, Y., and Shtienberg, D. 1995. Botrytis cinerea in greenhouse vegetables: Chemical, cultural, physiological and biological controls and their integration. Integr. Pest Manage. Rev. 1:15-29.

9. Hausbeck, M. K., and Pennypacker, S. P. 1991. Influence of grower activity and disease incidence on concentrations of airborne conidia of Botrytis cinerea among geranium stock plants. Plant Dis. 75:798-803.

10. Hausbeck, M. K., and Pennypacker, S. P. 1991. Influence of grower activity on concentrations of airborne conidia of Botrytis cinerea among geranium cuttings. Plant Dis. 75:1236-1243.

11. Ingram, D. M., and Meister, C. W. 2006. Managing Botrytis gray mold in greenhouse tomatoes using traditional and bio-fungicides. Online. Plant Health Prog. doi:10.1094/PHP-2006-0718-01-RS

12. Jarvis, W. R. 1992. Managing Diseases in Greenhouse Crops. American Phytopathological Society, St. Paul, MN.

13. Jewett, T. J., and Jarvis, W. R. 2001. Management of the greenhouse microclimate in relation to disease control: A review. Agronomie 21:351-366.

14. Jones, J. B., Jones, J. P., Stall, R. E., and Zitter, T. A., eds. 1991. Compendium of Tomato Diseases. American Phytopathological Society, St. Paul, MN

15. Leroux, P. 2004. Chemical control of Botrytis and its resistance to chemical fungicides. Pages 195-222 in: Botrytis: Biology, Pathology and Control. Y. Elad, B. Williamson, P. Tudzynski, and N. Delen, eds. Kluwer Academic Publishers, Dordrecht, The Netherlands.

16. Madden, L. V., Hughes, G., and van den Bosch, F. 2007. The Study of Plant Disease Epidemics. American Phytopathological Society, St. Paul, MN

17. Moorman, G. W., and Lease, R. J. 1992. Benzimidazole- and dicarboximide-resistant Botrytis cinerea from Pennsylvania greenhouses. Plant Dis. 76:477-480.

18. Nicot, P. C., and Baille, A. 1996. Integrated control of Botrytis cinerea on greenhouse tomatoes. Pages 169-189 in: Aerial Plant Surface Microbiology. C. E. Morris, P. C. Nicot, and C. Nguyen-The, eds. Plenum Press, New York.

19. O'Neill, T. M., Shtienberg, D., and Elad, Y. 1997. Effect of some host and microclimate factors on infection of tomato stems by Botrytis cinerea. Plant Dis. 81:36-40.

20. Rogers, S. L., Atkins, S. D., and West, J. S. 2009. Detection and quantification of airborne inoculum of Sclerotinia sclerotiorum using quantitative PCR. Plant Pathol. 58:324-331.

21. Shtienberg, D., Elad, Y., Niv, A., Nitzani, Y., and Kirshner, B. 1998. Significance of leaf infection by Botrytis cinerea in stem rotting of tomatoes grown in non-heated greenhouses. Eur. J. Plant Pathol. 104:753-763.

22. Tantau, H. J., and Lange, D. 2003. Greenhouse climate control: An approach for integrated pest management. Comput. Electron. Agric. 40:141-152.

23. ten Have, A., van Berloo, R., Lindhout, P., and van Kan, J. A. L. 2007. Partial stem and leaf resistance against the fungal pathogen Botrytis cinerea in wild relatives of tomato. Eur. J. Plant Pathol. 117:153-166.

24. Verhoeff, K. 1967. Studies on Botrytis cinerea in tomatoes. Influence of methods of deleafing on the occurrence of stem lesions. Neth. J. Plant Pathol. 73:117-120.

25. Verhoeff, K. 1968. Studies on Botrytis cinerea in tomatoes. Effect of soil nitrogen level and of methods of deleafing upon the occurrence of B. ciner$e a$ under commercial conditions. Neth. J. Plant Pathol. 74:184-192.

26. West, J. S., Atkins, S. D., and Fitt, B. D. L. 2009. Detection of airborne plant pathogens; halting epidemics before they start. Outlooks Pest Manage. 20:11-14. doi:10.1564/20feb05

27. Wilson, A. R. 1966. Infection of tomato stems by Botrytis cinerea Pers. ex. Fr. Acta Hortic. 4:135.

28. Yourman, L. F., and Jeffers, S. N. 1999. Resistance to benzimidazole and dicarboximide fungicides in greenhouse isolates of Botrytis cinerea. Plant Dis. 83:569-575. 